\title{
Public Health Challenges in Somachi Main Abattoir Owerri, Nigeria: A Review and Field Activity Report
}

\author{
Obidiegwu C. S, Chineke H. N, Ubajaka C. N, Adogu P. O. U
}

\begin{abstract}
Abattoir activities are known to pollute the environment, posing significant public health concerns. These activities predispose the workers and nearby communities to some communicable and non-communicable diseases. In the production of animal for food, more attention should be focused on the interactions between animal production and the environment. Meat production in the Somachi main abattoir, should be carried with the best of structures to produce wholesome and safe meat, avoid environmental pollution and circumvent human health risks especially for the sake of families and communities living close by. It is recommended that there should be immediate installation of necessary standard equipment and major functional units of the abattoir such as cold rooms, skinning machines, slaughtering machines, changing rooms for workers and toilets. In the medium/ long term, there should be appropriate technology should be developed, to take care of all the wastes generated in the abattoir, including abattoir wastewater, treatment and recycling for irrigation; and compost and biogas production.

The abattoir workers and management need regular updates of health information concerning the peculiar nature of their job with a view to preserving not just their health but also that of their customers and community in general.
\end{abstract}

Index Terms - Abattoir; Public Health challenges; Owerri; Nigeria

\section{INTRODUCTION}

\section{Review of the Ideal Abattoir}

An abattoir is a facility or a premise approved and registered by the controlling authority for hygienic slaughtering and inspection of animals, processing and effective preservation and storage of meat products for human consumption. It is ultimately derived from the French verb abattre, which means "to strike down" or "fell"[1] and it has existed as long as there have been settlements too large for individuals to rear their own stock for personal consumption. Animals are slaughtered in abattoirs for sale to the public. Abattoirs may be classified into categories depending on available facilities: Rural areas; Slaughter Slabs; and Townships: Slaughterhouses [2]. The animals most commonly slaughtered for food are cattle (beef and veal), sheep (lamb and mutton), pigs (pork), and poultry [1].

Slaughtering animals on a large scale poses significant logistical problems, animal welfare problems, public health

Published on July 8, 2019.

Obidiegwu C. S is with Department of Public Health, Imo State University, Owerri, Nigeria (E-mail: prosuperhealth50@gmail.com).

Chineke H. N is with Department of Community Medicine, Imo State University, Orlu, Nigeria (E-mail: hncfamilydoc@yahoo.com).

Ubajaka C. F is with Department of Community Medicine, Nnamdi Azikiwe University, Awka, Nigeria (E-mail: chika@grunzlink.com).

Adogu P. O. U is with Department of Community Medicine, Nnamdi Azikiwe University, Awka, Nigeria (E-mail: po.adogu@unizik.edu.ng). requirements, and environmental problems. Due to public aversion in many cultures, determining where to build slaughterhouses is also troubling.

The abattoir was first put into use in 1890 and it experienced some teething troubles, but nevertheless managed to make a lot of profit until the First World War. After the war, in 1922, the town of Anderlecht exercised its take-over right, as anticipated in the concession agreement. For the town, the trading activities of the markets and abattoirs formed a significant source of revenue for the postwar rebuilding work. In addition, the site worked as a magnet for other trading activities, bringing flourishing trade and prosperity to the district.

Sanitary Facilities: Water points, hoses, sterilizers for hand tools etc. and cleaning equipment must be provided in sufficient numbers. Where possible, sterilizers should be supplied with hot water instead of chemical disinfectants. Sanitary facilities must also include a sufficient number of toilets/latrines and arrangements for hand-washing or even possibilities for bathing (showering). These facilities must be kept clean and well maintained.

To avoid back-flow from toilets in case of flooding the toilet outlets must be separated from common waste water outlets. Areas/rooms for resting and eating may be required assuring that food for the personnel and the carcasses/meat cannot be mixed.

There should be a reasonable relationship between the size of slaughter facilities and the number of animals to be killed. Sufficient space for lairage and tripe and hide treatment is required. The space required for lairage will often depend on local and even climatic conditions. In specific areas it will only be possible to transport the animals in the dry season while slaughtering may only be carried out in the rainy season because of water requirements. Sufficient space is required to dig pits for condemned animals, compost stacks, lavatories etc., and for disposal of liquid and solid waste.

Buildings/facilities: These should be so constructed that clean and unclean processes and products do not mix. The floor must be hard, smooth and impervious, sloping sufficiently towards a drain thus allowing cleaning with water. Walls, if any, may be made of local construction materials. In certain dry areas walls are not necessary. Materials, which can be cleaned by water, are recommended, e.g. stone, lava blocks, bricks or concrete. Roofs if any may be constructed of materials available (tiles, corrugated iron, asbestos or aluminium). Roofing is recommended to protect and allow the slaughter process to be independent of the weather; to provide shade and keep down the internal temperature and to enable the collection of rainwater in water tanks.

The general slaughter process includes inspection and grading of carcass by a Veterinary inspector for quality and 
safety. Carcass is cut apart and the body parts separated. In a standard abattoir, meat cuts are quickly chilled to prevent the growth of microorganisms and to reduce meat spoilage while the meat awaits market demand for distribution. The remaining carcass may be further processed to extract any residual traces of meat while materials not destined for human consumption are sent to a rendering plant, and the meat is finally transported to local retail markets [3].

\section{ACTIVITIES IN THE ABATTOIR}

These include slaughtering of cows, goats and sheep; dividing of the carcasses into different parts; removal and cleaning of the intestines; leaning of the skin of the animals; meat inspection by meat inspectors from the vet nary office and cleaning of the slabs and drains [4].

Lairage: there should be sufficient space and a sufficient supply of potable water for drinking purposes. A spraying system where the animals can be cleaned before entering the slaughterhouse is recommended, if sufficient water is available. The floor should be constructed of concrete and sloping towards drains in order to facilitate cleaning.

Regulations concerning feeding and watering of the animals before slaughter should be considered.

Stunning, Slaughtering and Bleeding: These processes must, if possible, be separated from the operations which follow. If the blood is not intended for use it should be drained away into a separate pit and should not be allowed to drain into the waste water. The animals should be hoisted to facilitate bleeding and decrease the risk of contamination of the carcasses. This area should be constructed with a slope towards drains.

Scalding, Skinning, Dehairing or Plucking: The process varies according to animal (poultry, pigs and cattle). Skinning or dehairing may be carried out in a separate room/area or in the slaughtering place. However, it should be carried out separately from the evisceration process. The same principle applies to plucking of poultry. The unskinned/ undehaired carcass must never enter the clean area, but as soon as possible after skinning, dehairing, or plucking, it must be hygienically transferred to the clean area (evisceration room/or area). It is important to handle the carcass carefully to minimize contamination. To secure and improve cleanliness and efficiency hoists and overhead rails are required for the skinning/dehairing process. If hoists and overhead rails are not available, the carcasses should be kept above floor level by means of cradles. Procedures assuring cleaning of hoists, overhead rails and cradles should be established. Special rooms/areas should be available for treatment of hides.

Evisceration: During the evisceration process care should be taken to minimize contamination. Special care must be taken to avoid damaging the intestines. Edible organs must be handled in a hygienic way (stored/ removed in separate containers etc.). Waste must be removed rapidly from the floor in the evisceration room/area. A sufficient number of sterilizers for hand tools, knives, etc. must also be available in the evisceration area.

Chilling/Hanging: Carcasses may be chilled or divided in halves or quarters and then distributed for sale as soon as possible. When chilling is carried out, there must be sufficient chilling capacity and space to assure sufficient chilling. Carcasses can even be chilled when they are just hanging up and are air-dried, chilling being caused by evaporation.

Cutting /Deboning: If cutting and/or deboning is carried out care must be taken to minimize contamination of the meat. The carcasses must be cut, preferably hanging or on surfaces (tables, cutting planks, chopping blocks), which are regularly cleaned. A sufficient amount of sterilizers must be available for cleaning of hand tools, knives, etc. The meat must be removed and/or stored in clean containers, which solely are used for meat. Disposable containers will assure hygienic transport and storage, but will be costly [4]

Protective Gadgets for Abattoir Workers: These include raincoats and covered shoes that protect the feet; raincoat and other wears that can protect the body; hand gloves; ear muffs and ear plug; and face mask.

Challenges of Abattoir in Nigeria

Despite availability of legislative framework on animal slaughter in the country, diverse problems such as slaughtering animals on untidy floors, absence of stunning and ripening operations, inadequate slaughtering facilities, lack of sewage disposal systems, inadequate clean water supply abound with meat handling procedures in abattoir in this case report. Other common challenges include: Lack of a refrigeration system, inadequate transport system for meat products and lack of price incentives for quality.

Abattoirs are known all over the world to pollute the environment either directly or indirectly during various daily operations [5] The numerous waste and microbial organisms obtained during abattoir operation not only pose a significant challenge to effective environmental management but also are associated with decreased quality of life of human population living close to these abattoirs [6]. Abattoir operations produce a characteristic highly organic waste with relatively high levels of suspended solid, liquid and fat. The solid waste includes condemned meat, undigested ingests, bones, horns, hairs and aborted foetuses. The liquid waste is usually composed of dissolved solids, blood, gut contents, urine and water. Animal food is always microbiologically contaminated by organisms living in it naturally or entering it from the surroundings, such as those resulting from processing operations [7].

Where abattoir effluent-polluted waters are used to grow salad crops and vegetables, transmission of infections is bound to occur because animal wastes are known to contain pathogenic organisms, causing Salmonellosis, Leptospirosis, Tularemia, Foot and mouth disease and many more [8]. Abattoir activities and management have direct and indirect effects on the built-up environment and health of people especially residents in abattoir vicinity. There is a negative impact of abattoir activities on air and water qualities of surrounding residential areas; especially where effective waste disposal system is not practiced. Very poor meat inspection facilities and uncooperative attitude of butchers have also been reported in Nigerian abattoirs [9].

Environmental problems have increased with improper management practices being largely responsible for the gross pollution of the aquatic environment with parallel increase in water borne diseases especially typhoid, 
diarrhoea and dysentery. A German study reported that blood, one of the major dissolved pollutants in slaughterhouse wastewater, has a chemical oxygen demand (COD) of $375,000 \mathrm{mg} / \mathrm{L}[10]$. This impacts high organic pollutants on receiving waters consequently creating high competition for oxygen within the ecosystem. While the slaughtering of animals result in meat supply and useful byproducts like leather and skin, livestock waste spills can introduce enteric pathogens and excess nutrients into surface waters and can also contaminate ground waters [11].

\section{Rational for Field Activity Report}

The rational of this field activity report is to identify and address public health concerns of daily operation in Somachi main abattoir, Imo state, Nigeria. This is a government-owned and managed slaughter facility which has served the locality for upward of 20 years since inception. This practice, nonetheless, poses high risk of contamination of meat and meat products with harmful bacterial, viral, fungal and parasitic or chemical agents that can cause fatal disease in humans. Environmental problems have increased with improper management practices being largely responsible for the gross pollution of the aquatic environment with parallel increase in water borne diseases especially typhoid, diarrhea and dysentery. It was strongly recommend that adequate measures be taken by all stake holders to both fund and enforce existing legislations bordering on issues of food hygiene and community health.

General objectives: The purpose of this study was to ascertain the public health risk of daily operations at Somachi main abattoir, Imo state, Nigeria.

Specific objectives: 1) To identify the health problems associated with Somachi main abattoir in Egbu road, Imo state. 2) To ascertain the environmental status of the abattoir. 3) To ascertain the health status of the people in contact with the meat. 4) To verify the health status of the animals before slaughter.

\section{MethodOLOGY}

Study Area: This is Somachi main abattoir, located in Egbu road, Owerri, Imo state, Nigeria. This is a government-owned and managed slaughter facility which has served the locality for upward of 20 years since inception.

Study design: This was by regular weekend dawn visits to the abattoir for a period of 2 months mostly on Saturdays within the hours of $6.30 \mathrm{a} . \mathrm{m}$ to $10 \mathrm{a} . \mathrm{m}$. This was to observe and determine various activities and environment management problems at the abattoir.

Study population: The respondents included all individuals processing abattoir by-products at the time of study. The respondents were included in the study because they were readily available to provide necessary information about the abattoir in comparison to other busy abattoir workers like butchers and meat sellers.

Data Collection at the Abattoir Pre-tested, structured questionnaires were distributed to twenty-five (25) individuals processing various abattoir by-products (Skin/hide, bones, blood, horns and hooves and intestinal content) to obtain relevant information concerning activities at the abattoir but only twenty (20) returned it completely filled.

\section{Informed Consent}

A letter of introduction from the Department of Public Health, Imo State University was submitted to the facility to obtain clearance to enable the researchers have access to the abattoir. After being duly informed of the purpose and objectives of the study, verbal approval was given.

Limitation

It was difficult for the abattoir workers to allow snapshots of the abattoir but after few days of persuasion, the chairman of the abattoir, allowed photographs of some of the observed areas to be made and recorded.

\section{RESULT}

Qualitative findings: Observed activities inside the main slaughter hall

Abattoir workers were seen carrying out various activities in the slaughter hall, with none of them wearing protective clothing, and very few wearing rain-boots as form of protective wears. Others were seen without any protective wears.

The processes of bleeding, decapitation, evisceration and splitting of carcasses were carried out on the floor of the slaughter hall. Parts of the slaughtered animal carcasses were seen being carried out of the slaughter hall in most unhygienic manner leaving trails of blood on the floor and outside the abattoir (Plates 2 and 3). These abattoir workers are exposed to several infectious agents and hence can serve as potential vehicles of transmission of zoonotic infections outside the abattoir environment.

Meat and meat products are also prone to contamination with enteric pathogens as part of the gastrointestinal tract were seen being processed within the slaughter hall. Inappropriate waste disposal facilities at the abattoir also constitute a major problem. Decomposing foetuses/condemned carcasses from the slaughter hall were seen in exposed soak-away pits at the abattoir. The dilapidated drainage system leading from the slaughter hall to the soak away pits within the abattoir vicinity allows for only very slow movement of abattoir effluents, thus encouraging bacterial activities which can lead to the spread of diseases through vectors that can find the slow moving effluents as a good habitat. Studies have indicated that abattoir effluent contains lots of disease causing organisms. 
Quantitative Findings

Table 1. Data from Somachi Main Abattoir workers processing abattoir by-products

\begin{tabular}{lcc}
\hline Variables & Frequency & Percentage \\
\hline Ages in years & & \\
$26-40$ & 15 & 75.0 \\
$41-65$ & 50 & 25.0 \\
Sex & - & 100.0 \\
Male & 7 & - \\
Female & 10 & 35.0 \\
Educational status & 3 & 50.0 \\
Primary & & 15.0 \\
Secondary & - & \\
informal & - & - \\
How often do you go for medical check up & - & - \\
Monthly & 20 & - \\
Quarterly & 2 & 100.0 \\
Yearly & 18 & - \\
Only when ill & - & 100.0 \\
Knowledge of any disease contacted through handling animal by-products & \\
Yes & 20 & - \\
No & & \\
Any toilets and rest room available for use in the abattoir & 100.0 \\
Yes & 2 & 10.0 \\
No & 18 & 90.0 \\
Use any form of personal protective wears & & \\
Yes & 3 & 15.0 \\
No & 8 & 40.0 \\
Abattoir products processed by individuals & & 10.0 \\
Horns/hooves & 2 & 20.0 \\
Skin & 3 & \\
Bone & 4 & \\
Blood & & \\
Intestinal content & &
\end{tabular}

Twenty (20) Individuals processing different abattoir byproducts were interviewed using structured questionnaire to obtain certain information about the operation at the abattoir (Table 1). The respondents were males mostly within the age group of 26-40 years. They all stated that they were unaware of diseases that can be contacted within the abattoir vicinity and had never gone for routine medical check-up except when they fell ill. The poor knowledge of dangers associated with abattoir operation exhibited by these individuals make them carry out their daily activities without the need to protect themselves and go for regular medical check-ups. They also stated that there were no toilets facilities within the abattoir vicinity, hence making it difficult to maintain proper personal hygiene.

\section{HEALTH EDUCATION OF THE ABATTOIR WORKERS AND THE CHALLENGES:}

Some challenges were encountered in trying to educate them on health issues around their work. Most of the workers were more interested in the slaughtering and selling of their meat rather than giving in few minutes of their time to the health information. Most time, one had to wait till they finished slaughtering and selling out their meat before one could get their attention.

The health information was centred on the following:

1. The maintenance of good environmental conditions by disposing sewage and refuse in a sanitary manner within the abattoir

2. Maintenance of proper personal hygiene within the abattoir and the environment. The need to wear their protective clothing while at work and appropriate hand washing techniques were demonstrated. Also related risk factors like putting of contaminated hands and fingers into the mouth, nose or eyes; breathing-in of infectious aerosols/droplets from the smoky air; respiratory discharges such as coughs and sneezes, contaminated dust; splashes of blood and other body fluids into the eye and other mucous membranes, skin-penetrating injury caused by sharp objects like knife cuts and broken skin will be in direct contact with the microorganism were all emphasized. They were informed that individual differences in immune response determines the eventual outcome of host, parasites and environmental interactions while any pre-existing illness, might alter the immune status of any given individual.

3. They were told that hygiene problems are not limited to slaughtering but are also associated with incorrect processing and marketing practices. Also, occupational hygiene should necessitate hand-washing (and arms if necessary) before eating, drinking, smoking, using the telephone handsets, covering all new and existing cuts and bruises with waterproof dressings before starting work. If cuts occur immediate, washing with soap and running water and applying a waterproof dressing is recommended. Also, avoid contamination of meals by taking time-out for break time away from the main work area; wearing appropriate protective clothing such as waterproof/water-resistant protective clothing, plastic aprons, gloves, rubber boots/disposable overshoes to stop personal contamination and proper (safe) disposal of all contaminated waste.

4 Finally they were informed that food of animal origin tends to deteriorate more rapidly and become an important vehicle for gastrointestinal infections, thereby endangering consumers' health. Some of the human infections acquired from meat and poor handling of food animals were mentioned and explained.

\section{DISCUSSION}

Ideally, the design, operationalization and location of abattoirs may vary in size and sophistication depending on location and local government ordinance; but it should contain the following facilities or have them nearby: lairage, isolation block, slaughter hall, cooling hall, hide and skin store, guttery and tripery, offices, condemned meat room or apartment, laboratory and lavatory, dressing accommodation with lockers, laundry, and many more (Plates 1 and 4). Although, there are other abattoirs in Owerri, Somachi main abattoir was selected for this study based on its strategic location right at the city centre and also because it is the major abattoir which supplies about $65 \%$ of the meat for the city residents.

Unfortunately, diverse problems such as slaughtering animals on untidy floors, absence of stunning and ripening operations, inadequate slaughtering facilities, lack of sewage disposal systems, inadequate clean water supply abound with meat handling procedures in the abattoir. With inadequate slaughtering and disposal facilities, the abattoir has become a source of infection and pollution, attracting domestic and wild carnivores, rodents and flies, which are vectors of diseases. Since inception in May1999, no renovation has taken place there; the building is threatening to collapse.

Other common challenges include: Lack of a refrigeration system, inadequate transport system for meat products and lack of price incentives for quality. The slaughter slab is dilapidated and laden with inadequacies such as lack of adequate water supply, unsatisfactory waste disposal system (Plates 11, 13,16), poor drainage system and lack of facilities for the collection and disposal of 
wastes. Other sub-standard facilities and procedures include inadequate supervision of animal handling, slaughter and processing; and lack of proper meat inspection. It was observed that some of the slaughtered animals were sick, giving the impression that the urge to make money far outweighs the desire to ensure public health and safety.

It was also observed that the breakdown of the generating set used to pump water, compels the abattoir management to procure water from local hawkers in kegs and stored in empty drums standing by the slaughter slabs. This was never an adequate contingency plan for sanitary activities at the site; and this explains the unsightly damming of sewage from the slab for initial washes of viscera before final-wash with relatively clean water (see Plates 9-13).

If the meat and meat products are contaminated with waste products which are potentially hazardous at the time of slaughter and processing, there is a very high risk of their becoming contaminated with harmful bacteria, such as E.coli O157, Campylobacter and Salmonella. Research results have shown that the dirtier the hides and environment, the greater the potential for carcass contamination and the higher the risk to human health [12]. Wet hides and environment especially increase the risk because bacteria may be transferred more readily. E. coli O157, Salmonella and Campylobacter can be shed in animal dung. Such harmful bacteria may not be visibly detected before slaughter [13]. Very small numbers of E. coli O157 can cause severe or even fatal disease in humans.

Many large slaughterhouses have permanent personnel performing all work in the slaughterhouses [4]. Organization will depend on the type of production. Where personnel are permanent, a few lessons regarding process hygiene, personal hygiene, and cleaning and disinfection may be given. Ideally, personnel should be organized in a way that part of the staff is occupied with cleaning and disinfection. This group of personnel must be educated and trained especially in cleaning and disinfection procedures as well as general hygiene.

Where the slaughterhouse/slaughter facilities cover the need for slaughtering in big areas in developing countries, the slaughterhouse is often owned by municipalities and organized with a manager and no permanent staff. Slaughtering is done by local butchers and a team employed by these butchers and thus it will be difficult to give them sufficient education and training in hygiene.

It is therefore recommended that the manager of the slaughterhouse/slaughter facilities employ a team which is responsible for maintenance of a hygienic standard. This team should do some clearing and cleaning during slaughtering hours or instruct the butchers and workers to do this during and after slaughtering. This team will be responsible for cleaning and disinfection at the end of the working day and in maintaining the hygienic standard.

Poor managerial approach is common in this Somachi Main Abattoir such as: 1) State legislations not enforced; 2) Local government authorities only interested in revenue collection rather than good management and maintenance of this Somachi Main Abattoir; 3) Managers often not properly trained or committed; 4) Inconsistent government policies and funding, non -existence of insurance or compensation schemes for butchers and other stake holders. Persistence of the just mentioned problems requires basic measures to ameliorate them.

\section{CONCLUSION}

The daily operation at Somachi Main Abattoir predisposes the public to health hazards and there is need to maintain accepted international practices in abattoir operation.

In the production of animal for food, more attention should be focused on the interactions between animal production and the environment, realizing environmental conditions and structures in animal production, which not only seek to produce wholesome and safe animal food but should also avoid environmental pollution and the associated human health risks especial for the sake of families living close to this Somachi Main Abattoir.

\section{RECOMMENDATIONS}

1. The government needs to rebuild this Somachi Main Abattoir because the building is about to collapse. The roof of the bulding has also gone off.

2. The government should ensure Installation of necessary standard equipment and major functional units of the abattoir such as cold rooms, skinning machines, slaughtering machines, changing rooms for workers and Toilets.

3. Enforcement of existing health and hygiene regulations;

4. The government should develop appropriate technology, which will take care of all the wastes being generated in the abattoir, including abattoir wastewater treatment and recycling for irrigation; and Compost and biogas production.

5. Thorough and adequate training on sustainable animal production for the people involved in animal trade from farms to abattoirs and slaughterhouses, including periodic continuing education programs.

\section{APPENDIX}

June 2: Visitation of the Abattoir

June 9: Meeting with the chairman Mr Opera Chima (leader of the butchers)

June 16: Inspecting the Animals before they were butchered June 23: Mentoring on personal hygiene

June 30: Mentoring on Animal production hygiene

July 7: Mentoring on Waste Disposal

July 14: Mentoring on Sewage Disposal

July 21: Interactive sessions and monitoring the Abattoir workers for improvement on hygiene

\section{ACKNOWLEDGMENT}

Obidiegwu C. S thanks Mr Opera Chima, leader of the Butchers at the abattoir for granting us unlimited access to the abattoir to carry out the study.

\section{REFERENCES}

[1] Gail A. Eisnitz. Slaughterhouse. Prometheus Books, New York: 1997: 310-12 
[2] Blood D. C. \& Studdert, V. P. Bailliere's comprehensive veterinary Dictionary Oval Road, London NW1 7DX. 1990: 24-28.

[3] Merck Veterinary Manual (1998). Merck \& Co. Inc. White house station, USA.1998;8: 2305

[4] Eriksens P.J. FAO Slaughter house and Slaughters.1978:8-9

[5] Adelagan, J.A. Environmental policy and slaughter house waste in Nigeria. In: Proceedings of the 28th WEDC conference, India; 2002.

[6] Adeyemo, O.K. Unhygienic operations of a city abattoir in South Western Nigeria: Environmental implication.2002 4(1):23-27.

[7] Akinro AO, Ologunagba B and Olotu Y. Environmental implications of unhygienic operation of a city abattoir in Akure, Western Nigeria. Journal of Engineering and Applied Sciences, 2009; 4 (9):60-62

[8] Adebowale O. O, Adedamola J, Adeyemo O, Eniola K. Potential Bacterial Zoonotic Pathogens Isolated from a Major Abattoir and its Receiving Surface Water in Abeokuta, Nigeria Alexandria Journal of Veterinary Sciences 2016; 50(1):94-98

[9] Otolorin, G. R., Okolocha1, E.C., Ameh, V. O., Mshelbwala, P. P2. Danjuma, F. A3 and Dzikwi, A. A. Public Health Risk of Abattoir Operation in Zango Abattoir Zaria, Kaduna State Nigeria. Annual Research \& Review in Biology. 2015; 5(2): 139-146.

[10] Tritt, W.P, Schuchardt, F. Materials flow and possibilities of treating liquid and solid wastes from slaughterhouses in Germany. Bio resource Technology. 1992;41:235-245.

[11] Schlech, W.F., Lavigne P.M. \& Bortolussi, R.A. Epidemic listeriosis evidence for transmission by food. The New England Journal of Medicine. 2005; 308:203-206

[12] Duffy G, Burgess CM, Bolton DJ. A review of factors that affect transmission and survival of verocytotoxigenic Escherichia coli in the European farm to fork beef chain. Meat Science, 2014; 97 (3):375383 https://doi.org/10.1016/j.meatsci.2014.01.009

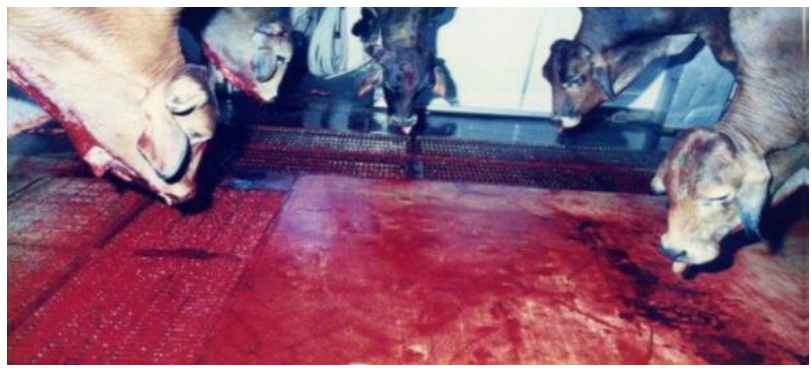

Plate 1: Slaughter on rails in a standard abattoir

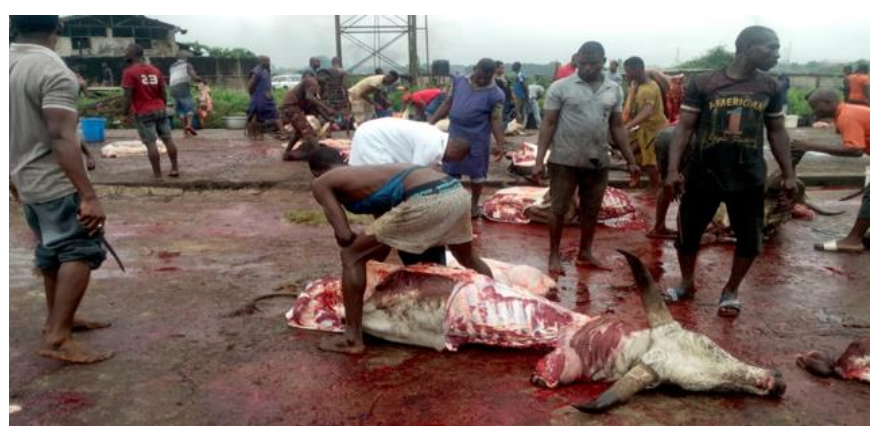

Plate 2: Slaughtering done on the floor in Somachi main abattoir

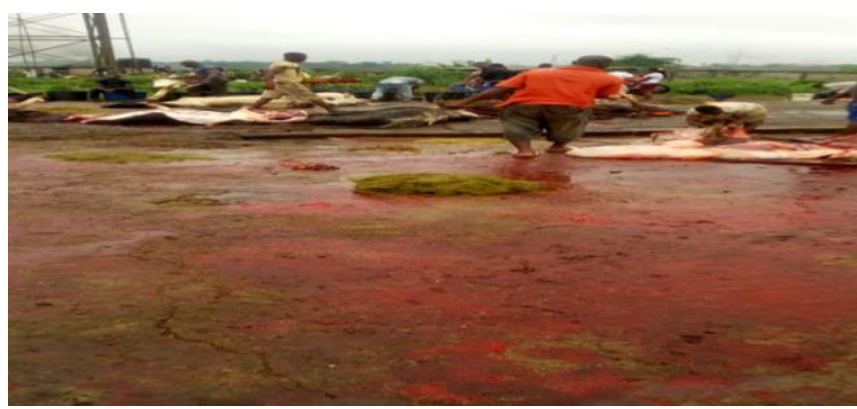

Plate 3: Workers not protected in any way! No coverall, no boots, no apron. Slab is absolutely messy (Plate 2 and 3)
[13] Alline R. P and Sperandio P, Sperandio V. Shiga toxin in enterohemorrhagic E.coli: regulation and novel anti-virulence strategies. Front. Cell. Infect. Microbiol., 07 June 2012| https://doi.org/10.3389/fcimb.2012.00081

[14] R. J. Vidmar. (August 1992). On the use of atmospheric plasmas as electromagnetic reflectors. IEEE Trans. Plasma Sci. [Online]. 21(3). pp.876-880.Available:http://www.halcyon.com/pub/journals/ 21ps03vidmar

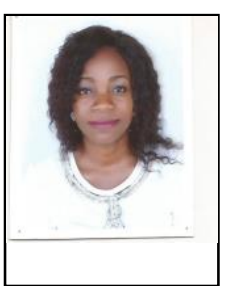

Name: Obidiegwu Chidubem Sharon (Lead author) Place of birth: Owerri, Imo state, Nigeria. Date of birth: 21 March 1986. Educational background: Masters of Public Health (MPH), Imo state University (IMSU), Nigeria...November 2018 Bachelor of Medical Lab Science (B.MLS), IMSU, Nigeria...December 2010

Work Experience: She currently works as Medica Laboratory Scientist in the Ministry of Health, Imo state, Nigeria. She has previously worked in Ebonyi and Ondo states of Nigeria in some private laboratory facilities. Current research interest is Infectious disease epidemiology.

Membership of Professional Societies: Mrs Obidiegwu is a member of Association of Medical Laboratory Scientists of Nigeria.

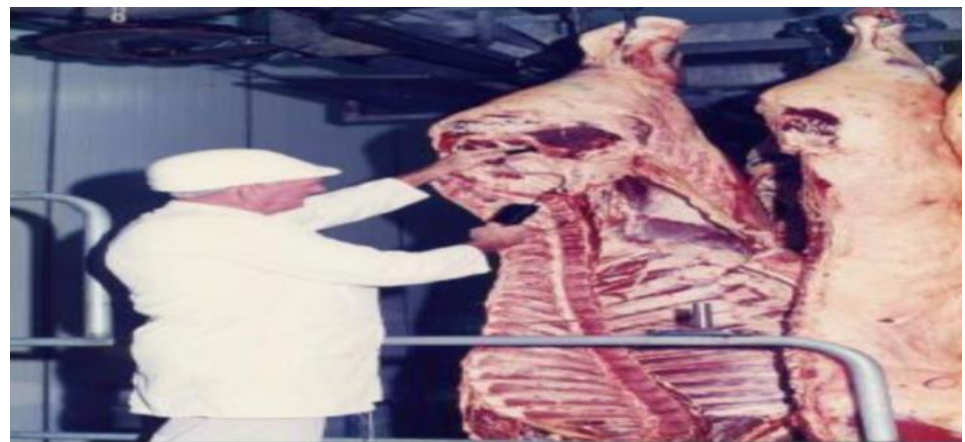

Plate 4: Carcass is inspected in a Standard abattoir

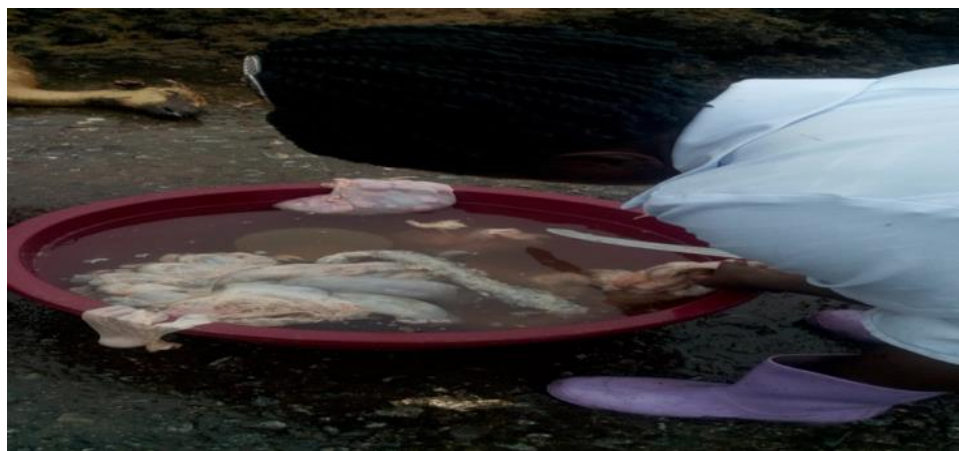

Plate 5: Carcass is given little or no veterinary inspection (in Somachi main abattoir) 


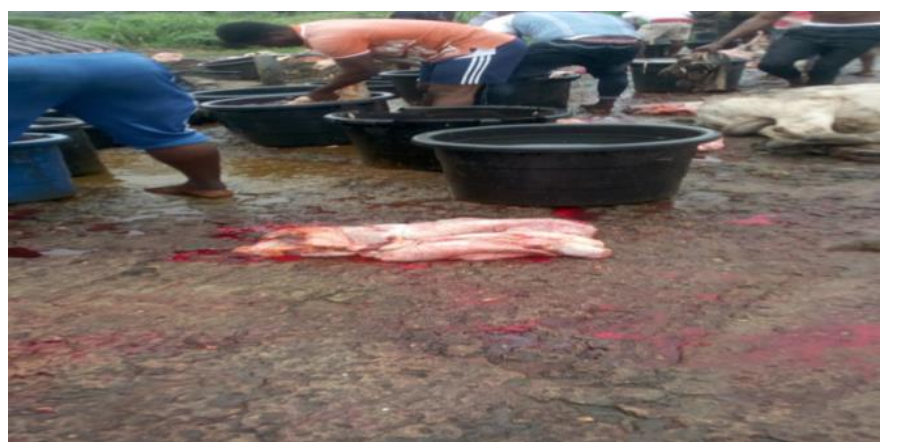

Plate 6: Evisceration and washing of offal in the abattoir. Note; untidy and awkward nature of each process (Plate 6, 7,8)

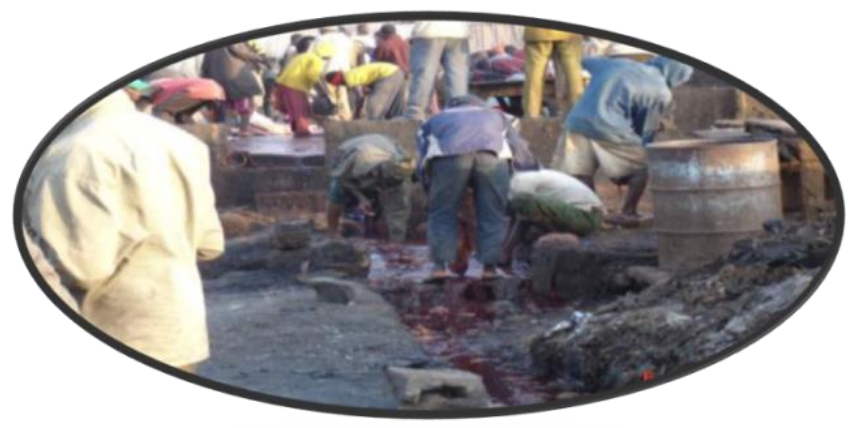

Table 10

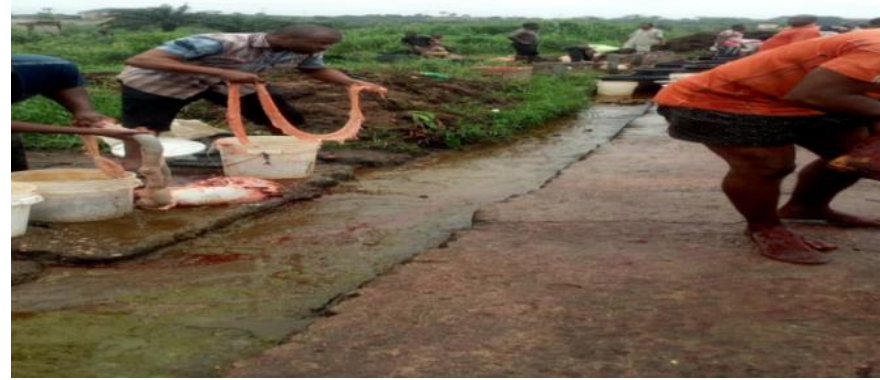

Plate 7

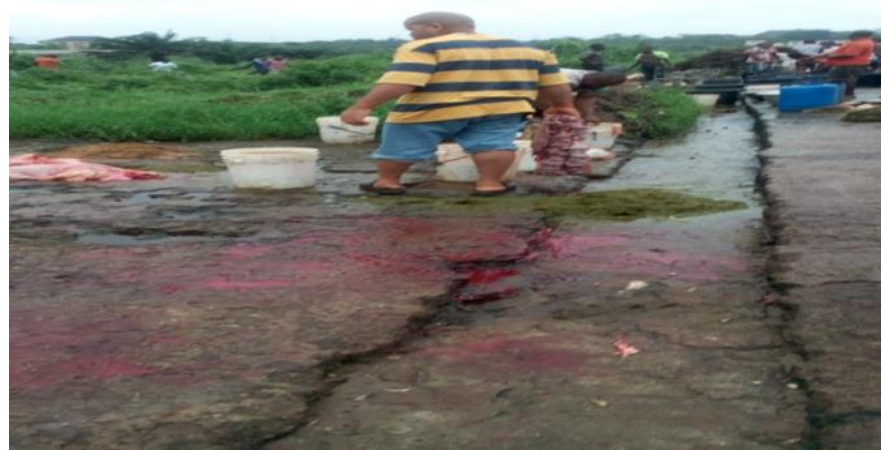

Plate 8

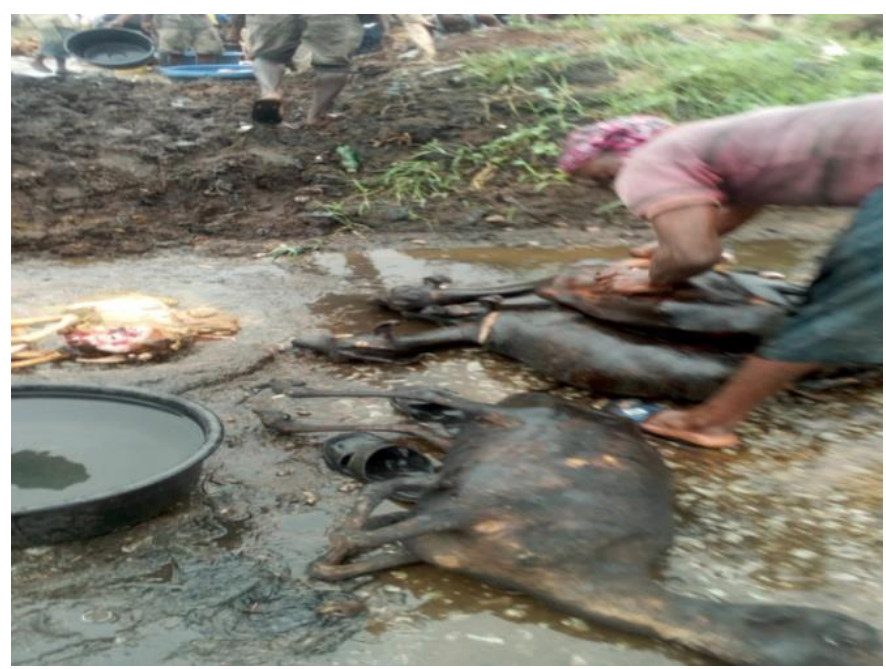

Plate 9

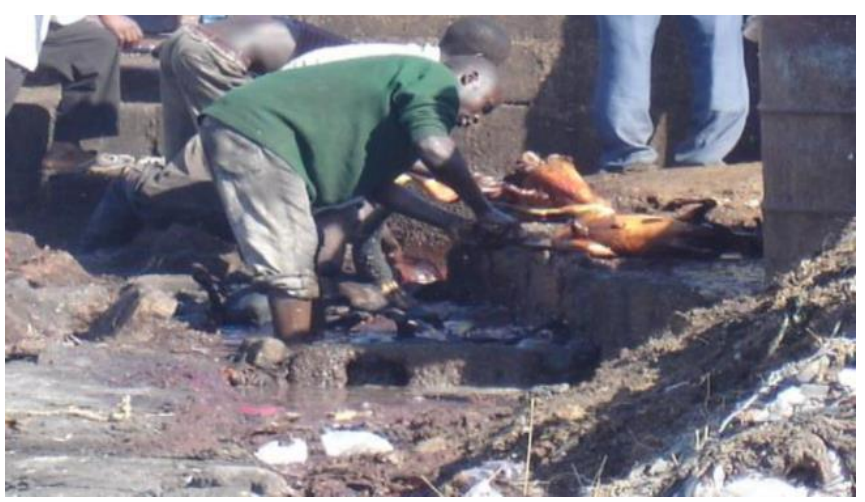

Plate 11

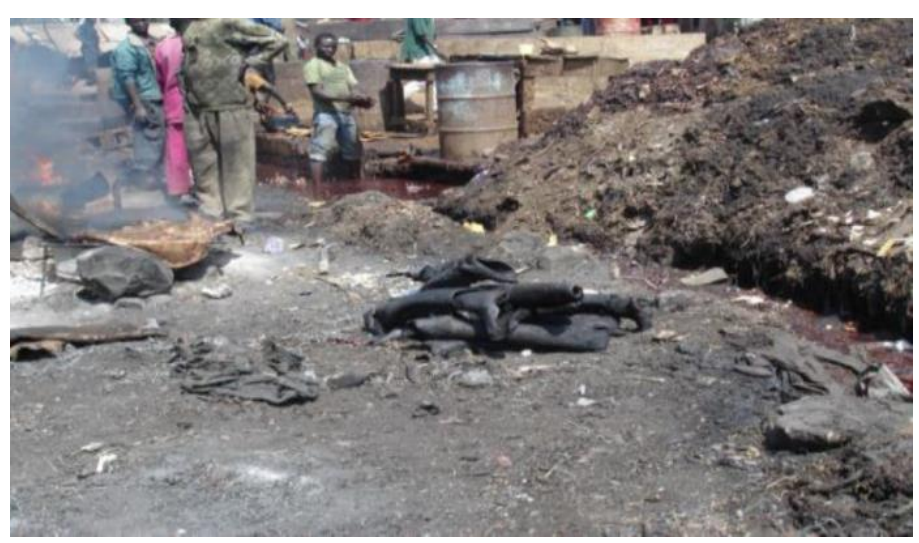

Plate 12

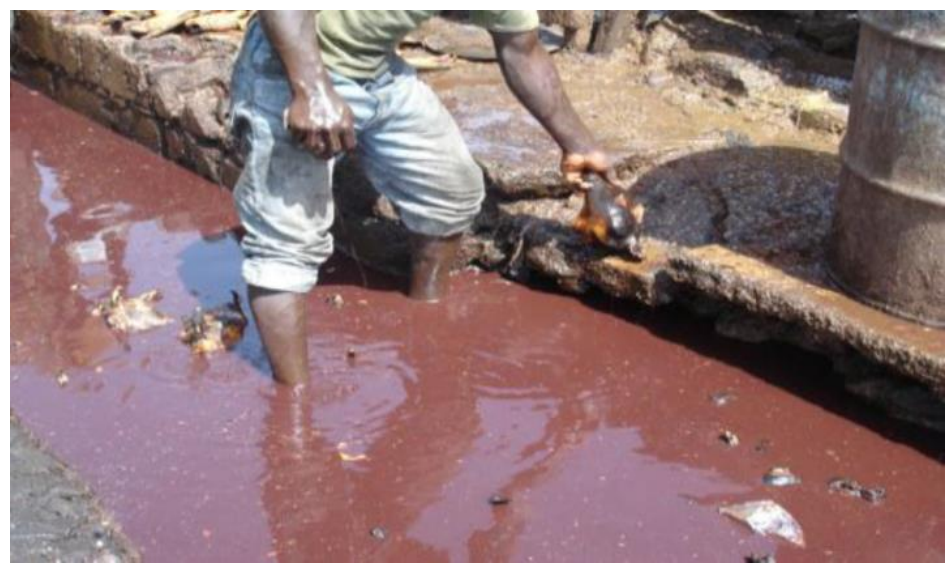

Plate 13: Roasting and washing of cattle hides, heads, legs and goats in dammed abattoir sewage (Plates 9-13) 